\title{
RESENHAS
}

\section{A LDB E A PSICOLOGIA ESCOLAR}

\section{Moacir WUO ${ }^{1}$}

O título Lei e Psicologia Escolar já chama a atenção e convida a um de debate.

De um lado a Psicologia Escolar como área de conhecimento, para a qual estão voltadas atenções e preocupações acadêmicas associadas a um crescente interesse entre os psicólogos e aumento de produção literária, que ainda não tem reconhecimento legal de suas funções e atribuições mas mantém um vivo e intenso debate sobre a formação e atuação do profissional Psicólogo Escolar. De outro lado a LDB - Lei de Diretrizes e Bases $n^{\circ}$ 9394/96 - que define os objetivos e as prioridades para o desenvolvimento do projeto de educação nacional em todos os níveis e que vem suscitando discussões uma vez que, para alguns segmentos, a LDB não representa as aspirações e necessidades da sociedade brasileira; enquanto que, para outros, a mesma LDB representa um avanço na concepção das referências essenciais do processo educacional. De qualquer maneira, a LDB é uma lei que estabelece mudanças.

É, portanto, neste cenário polêmico e oportuno que Raquel Souza Lobo Guzzo, Doutora em Psicologia Escolar, pesquisadora, comprometida com a formação e atuação do Psicólogo Escolar e representante da classe em instituições e associações como a ISP (International School Psychology Association) e ABRAPEE

\begin{abstract}
(Associação Brasileira de Psicologia Escolar e Educacional), na qualidade de organizadora, reúna pesquisadoras de reconhecida experiência e autoridade científica e não menos comprometidas com a formação e atuação do Psicólogo Escolar e com os rumos da Psicologia Escolar no Brasil, e convida o leitor a participar de questionamentos que necessariamente se interpõem entre a Psicologia Escolar e a LDB.

O primeiro capítulo de autoria de Zilda Aparecida Pereira Dei Prete, sem negar avanços da atual LDB em relação as Leis 5540/68 e 5692/71, apresenta denúncias de omissões, contradições, conflitos de interesses e insatisfações geradas por essa mesma LDB. Destacam-se a suspensão do conceito de Sistema Nacional de Educação e do Fórum Nacional de Educação: a descaracterização do Conselho Nacional de Educação e a ausência de um regime jurídico único para os professores e da responsabilidade da União pela manutenção das Universidades.
\end{abstract}

Quanto à atuação do Psicólogo Escolar Del Prete indica não ocorrer alterações na lei uma vez que persiste a "visão equivocada e restritiva" da Psicologia na área educacional. Essa restrição é evidenciada, porque não é prevista a inclusão do Psicólogo no quadro funcional da escola. As conseqüências dessa restrição seriam as dificuldades para a conver-

\footnotetext{
(1) Doutorando em Psicologia Escolar pela PUC-Campinas. Centro Estadual de Educação Tecnológica "Paula Souza" Universidade de Mogi das Cruzes Endereço para correspondência: Rua Júlio de C.P. Pacca, 115, Mogi Moderno, CEP 08717-560, Mogi das Cruzes, SP. Telefone: (OXX11)4796.1237 - Fax: (OXX11)4798.2017 - E-mail::isowuo@ibm.net
} 
são dos objetivos proclamados na lei em ações concretas, por meio de um projeto pedagógico, dada a falta de condições e capacidades que ora, as escolas, em geral, apresentam.

Ao mesmo tempo que Dei Prete apresenta um quadro com as alternativas e possibilidades para a atuação do Psicólogo Escolar, recomenda que a formação do Psicólogo deve estar voltada para uma atuação efetiva em todos os contextos educativos da sociedade.

A Educação Especial conquista espaços na LDB, mas o que se depreende das postulações de Ana Maria Torezan, no capítulo dois, é o caráter opcional e não obrigatório para esse tipo de Educação. As discussões sobre as necessidades especiais e educacionais assim como a condução dos processos de ensino-aprendizagem que possam garantir o desenvolvimento de interações sociais e a inserção plena à vida comum daqueles que sentem essas necessidades, tema que vem sendo discutido em conferências internacionais, não encontra respaldo adequado na atual política educacional brasileira. A dicotomia entre as concepções de "ensinar" e "aprender" na escola é mantida em detrimento da mudança do foco de atenção para o processo ensino-aprendizagem. Nesse sentido, a Autora discute a necessidade do redirecionamento da formação e atuação do Psicólogo para que ele possa fazer uso dos conhecimentos teóricos disponíveis com o intuito de consolidar as ações e mudanças institucionais e pedagógicas com relação à pessoa com algum tipo de deficiência.

Vera Lúcia Trindade Gomes, a partir dos dados de sua tese de doutorado, descreve e debate as implicações geradas entre a formação, a teoria e a prática profissional do Psicólogo Escolar. Tanto os países pobres como os países ricos manifestam a necessidade do Psicólogo Escolar e indicam que suas funções devem estar voltadas para minimizar problemas tais como fracasso escolar, evasão, analfabetismo; comportamentos inadequados em sala-de-aula; violência, entre outros, muitas vezes decorrentes de contextos sócio-políticos e históricos de cada país.

As pesquisas de campo da Autora apresentam informações importantes como aquelas relacionadas às queixas sobre a atuação do Psicólogo na escola. Essas queixas podem ser enquadradas em dois grupos: a) as condições funcionais do Psicólogo e b) incapacidade do Psicólogo de atender as necessidades da escola e dos alunos. Decorre, portando, do segundo grupo de queixas, as questões sobre a formação do Psicólogo Escolar, sobre as definições e comprometimentos de sua atuação. Dessa forma é cobrada das Universidades, agências de formação do Psicólogo, a ampliação da atitude científica e da formação de vínculos entre a teoria e a realidade social.

A análise da atuação do Psicólogo, na rede oficial de ensino, é feita por Sandra Francesca Conte de Almeida. Importantes indicadores da identidade e da prática do Psicólogo no cotidiano escolar são produtos dessa análise. Contradições, desajustes entre referencial teórico e associação entre a teoria e prática denunciam atividades de profissionais descontextualizados e acríticos.

As definições de responsabilidades, especificidades profissionais e identidades do Psicólogo Escolar necessitam ser resgatadas e reconstruídas com ênfase nas competências técnicas e éticas. Esse resgate é necessário, segundo Almeida, devido à crise de identidade que sofre o Psicólogo Escolar cuja origem advém de sua formação associada ao modelo clínico-terapêutico e da dissociação entre indivíduo e sociedade.

Os caminhos apontados por Almeida, para a superação de tais problemas, passam pela construção de projetos de atuação do Psicólogo Escolar orientados por uma perspectiva teórica, explícita e com finalidades preventivas. Para que se busque uma redefinição de representações sociais e a criação de espaços reflexivos na "praxis" educacional. 
O capítulo cinco é uma pausa para analisar e refletir sobre a inserção social do Psicólogo, para fazer um balanço das mudanças e dimensões sociais atuais e rever objetivos e direcionamentos a seguir. É assim que Maria Helena Novaes conduz o leitor mostrando, no âmbito da sociedade, para onde devem ser voltadas as atenções e quais os pontos relevantes que exigem determinação profissional e aplicação de conhecimentos científicos oriundos de pesquisas dessa mesma sociedade. Sugere a ampliação da formação do Psicólogo Escolar, da visão e da atuação em processos educacionais informais, por meio de recursos já construídos pela sociedade e que necessitam ser valorizados, revitalizados e incluídos no processo ensino-aprendizagem. A busca de novos e criativos caminhos implica na definição de identidades, renovação de práticas profissionais e investimentos na formação acadêmica.

De maneira pragmática e objetiva, Geraldina Porto Witter discute as relações entre a Psicologia Escolar no Ensino Superior e a LDB. Além de indicar as inserções possíveis e esperadas do Psicólogo Escolar no processo educacional, a partir das orientações da LDB. A Autora especifica que conhecimentos básicos são necessários para que o Psicólogo Escolar possa desempenhar os múltiplos papéis e funções nesse processo, lembrando que esses papéis envolvem atividades que vão da educação básica até a produção de conhecimentos científicos ea atuação acadêmica nas Universidades.

Nessa concepção ampla, o Psicólogo Escolar deve ser um profissional dinâmico, crítico, dotado de habilidades, competências e capacidades para abrir espaços e contribuir significativamente para a qualidade da educação. Embora Witter, modestamente indique não ter analisado exaustivamente as relações entre a LDB e o ensino superior deixa claro quais as possibilidades explícitas, implícitas e subjacentes às funções do Psicólogo Escolar. Não só indica caminhos, mas apresenta importantes e objetivas informações de como deve ser instrumentalizado o Psicólogo Escolar na sua formação e quais as incumbências e responsabilidades das Universidades para esse mister. Aponta a necessidade de se estabelecer normas e padrões de serviços tanto pelas instituições estatais como pelas associações profissionais.

O capítulo de número sete, que encerra a obra, de autoria de Guzzo, apresenta um quadro amargo, realista da educação brasileira, produto de políticas demagógicas, equivocadas e casuísticas. É possível identificar, no discurso da Autora, pelo menos três pontos relevantes: 1) o caráter político-social que envolve a crise econômica e a falta de transparência de setores governamentais e do legislativo para com a sociedade brasileira, mais notadamente, a científica que detém a capacidade técnica para responder, propor e analisar criticamente as propostas atuais da política educacional; essa falta de transparência compromete princípios básicos da ordem democrática ; 2) o atual quadro de degradação da rede pública de ensino em todos os níveis que obriga a sociedade a buscar alguma qualidade no ensino privado que, por sua vez, também não dispõe de recursos técnicos para garantir a formação integral dos estudantes e, por razões óbvias, é incapaz de atender a maioria da população e 3) a formação e atuação do Psicólogo Escolar principalmente nas questões que envolvem o alcance da sua atuação, isto é, atendimento das necessidades educacionais desde a educação infantil até as Universidades.

A discussão desses pontos evidencia a necessidade da criação de um paradigma de atuação do Psicólogo Escolar, a partir de uma formação sólida com compreensão das dimensões sociais e políticas do processo educacional.

A virtude da obra é trazer à discussão os diversos aspectos da LDB nos quais a sociedade em geral, não só a Psicologia Escolar e a comunidade acadêmica e os setores envolvi- 
dos diretamente com o processo educacional, devem se debruçar no sentido de avaliar as conseqüências e as possibilidades de auferir dividendos para a melhoria da qualidade do ensino. Os temas são tratados com competência, autoridade científica e sem superficialidades. Todos os autores mantêm uma linha básica sobre a formação e atuação do Psicólogo Escolar, às vezes, um tanto severa o que deixa transparecer as preocupações com as conquistas de espaço na área educacional.

Registre-se que, há muito, a atuação da Psicologia Escolar nos países de primeiro mundo e em vários países pobres é uma realidade. Por esse motivo, embora não tenha sido o propósito da obra, seria interessante ter incluído o quanto a Psicologia Escolar já tem contribuído nas diversas áreas educacionais e na produção científica no Brasil, para que o leitor possa avaliar a importância e a necessidade da Psicologia Escolar no processo educacional. O debate franco apresentado nesta obra deve servir de exemplo e de estímulo para que as demais áreas educacionais revejam seus posicionamentos neste momento de mudanças propostas pela LDB.

Pode-se considerar uma leitura obrigatória para acadêmicos e profissionais da área de Psicologia e, principalmente, para os especialistas em educação e administradores que almejam consolidar as diretrizes educacionais previstas na LDB com competência e responsabilidade social. 